\title{
Early Steps Toward Inertial Fusion Energy (IFE) (1952 to 1962)
}

\author{
John H. Nuckolls
}

June 12, 1998

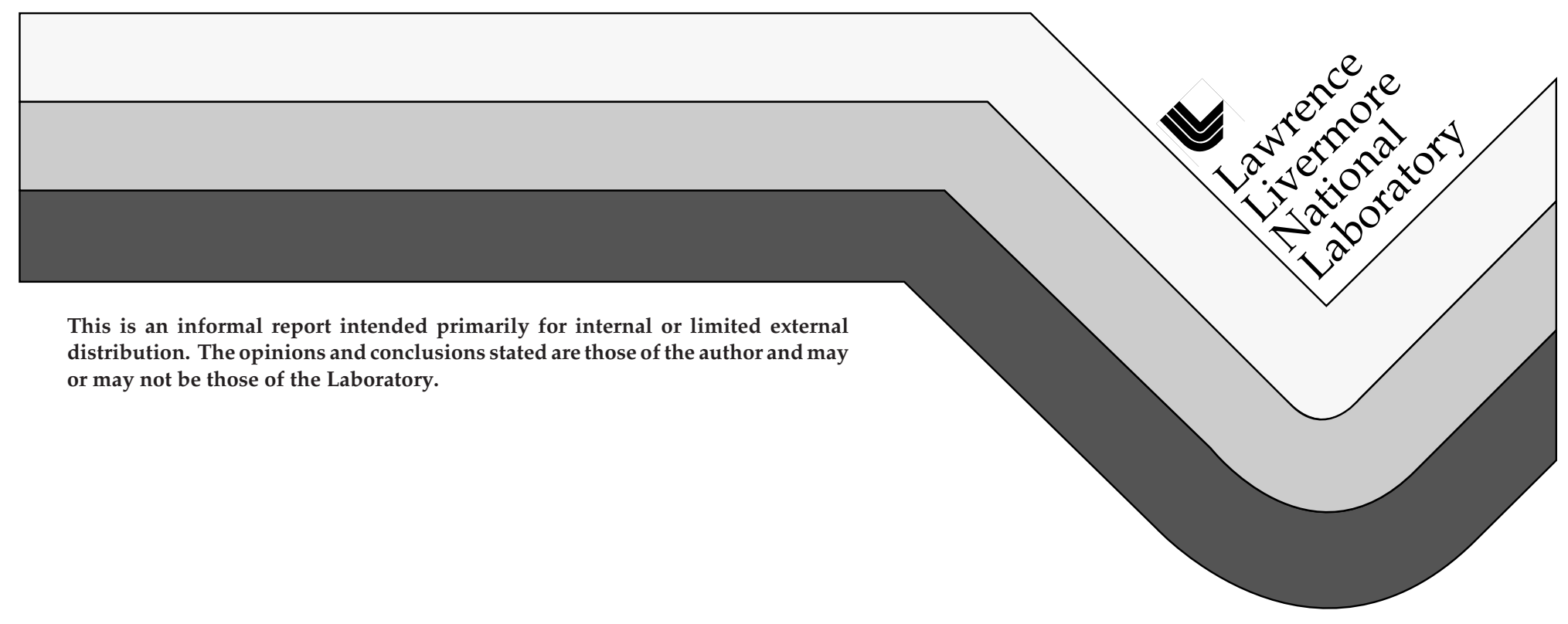




\section{DISCLAIMER}

This document was prepared as an account of work sponsored by an agency of the United States Government. Neither the United States Government nor the University of California nor any of their employees, makes any warranty, express or implied, or assumes any legal liability or responsibility for the accuracy, completeness, or usefulness of any information, apparatus, product, or process disclosed, or represents that its use would not infringe privately owned rights. Reference herein to any specific commercial product, process, or service by trade name, trademark, manufacturer, or otherwise, does not necessarily constitute or imply its endorsement, recommendation, or favoring by the United States Government or the University of California. The views and opinions of authors expressed herein do not necessarily state or reflect those of the United States Government or the University of California, and shall not be used for advertising or product endorsement purposes.

This report has been reproduced

directly from the best available copy.

Available to DOE and DOE contractors from the

Office of Scientific and Technical Information

P.O. Box 62, Oak Ridge, TN 37831

Prices available from (423) 576-8401

Available to the public from the

National Technical Information Service

U.S. Department of Commerce

5285 Port Royal Rd.

Springfield, VA 22161 


\section{Early Steps Toward Inertial Fusion Energy (IFE) 1952-1962*}

John H. Nuckolls

In late 1950, Edward Teller at Los Alamos conceived a two-stage radiation implosion scheme for high-yield thermonuclear weapons. A fission primary and a thermonuclear secondary are located inside a radiation case; thermal radiation from the exploding primary is channeled by the radiation case to implode the secondary.

In 1957, Teller and colleagues at Livermore explored several peaceful applications of nuclear explosives. We evaluated the feasibility of producing commercial power by the explosion of megaton yield $\mathrm{TN}$ devices in a onethousand-foot diameter, steam-filled cavity in granite. The large size of the cavity and the accumulation of fissile material from exploded primaries led me to address two key questions:

(1) What is the smallest possible fusion explosion with high enough energy gain for commercial power production $?^{* *}($ gain $=$ output/input)

(2) How can a minimum size high gain fusion explosion be ignited without use of a fission primary?

* Work performed under the auspices of the U.S. Department of Energy by Lawrence Livermore National Laboratory under Contract W-7405-Eng-48.

* * The smallest possible nuclear explosion is a fusion explosion, and not a fission explosion, because DT (the most reactive fusion fuel) burns efficiently at a $\rho R$ of one gram per $\mathrm{cm}^{2}$, whereas a 10-100 fold higher $\rho \mathrm{R}$ is needed to achieve criticality of a fission system. 
I proposed a novel scheme: implode a milligram of DT to super high densities by a radiation implosion in a tiny hohlraum energized by a nonnuclear primary external to the hohlraum - an efficient, stand-off, repetitive "primary" (known today as a "driver"). (Figures 1,2)

This scheme exploits the leverage and feasibility of compressing fusion fuel to extremely high densities - one thousand fold compression reduces the fusion "critical mass" one million fold! And the minimum energy required to compress DT 1000 fold is only a few percent of the energy required to heat DT to ignition temperature. Energetically high compressions are almost "free". TN propagation is utilized to fully exploit the compressibility of DT.

The powerful advantages of mini-radiation implosions are simply understood. An implosion amplifies energy densities, including temperatures. DT ignition temperatures are several Kev. Radiation temperatures which will implode fusion capsules to several Kev are ten times smaller - a few tenths of a Kev. Obviously, it is much easier to reach ten-fold smaller temperatures - since energy losses increase with a high power of the temperature.

The radiation implosion approach makes possible high compression and ignition of very small DT masses - by generating symmetric implosions, reducing the growth of fluid instabilities, and generating high implosion pressures and velocities. Symmetry is enhanced because the velocity of radiant energy in the hohlraum is a thousand times larger than the fusion 
capsule implosion velocity. Stability is enhanced because thermal radiation rapidly ablates the unstable surface where implosion pressures are generated. Ablation pressures greater than $100 \mathrm{Mb}$ can be generated by several hundred ev radiation temperatures. Corresponding material sound speeds are high enough so that implosion velocities of general hundred $\mathrm{Km} / \mathrm{s}$ can be efficiently generated.

The enhancement of symmetry, stability, implosion velocity and pressure makes possible the compression of DT to very high densities greater then 1000 times liquid density.

Figures 3 and 4 summarize the chronology of our early steps toward IFE. I will discuss the elements of this chronology in the remainder of my talk.

In early 1960, I completed computer calculations of the radiation implosion, ignition, and efficient burn of $1 \mathrm{mg}$ of DT. (Figure 5) The initial density of the DT enclosed by a thin spherical high density shell was $0.01 \mathrm{~g} / \mathrm{cm}^{3}$, sufficiently low to reduce the radiation temperature necessary to drive the implosion to $240 \mathrm{ev}$, and reduce energy losses to the hohlraum. ${ }^{*}$ The DT was imploded to several hundred times liquid density and ignited. The gain was about 10 (5 MJ input, $50 \mathrm{MJ}$ fusion output). Pulse shaping and TN propagation were not utilized. Improvements in stability and gain were achieved later in 1960.

Hohlraum losses decline rapidly with decreasing radiation temperature because the radiation flux is proportional to the fourth power of temperature; and in the few hundred ev region, the opacity of wall material varies inversely with the temperature squared. 
In Spring and Summer 1960, before the invention of the laser, I considered possible stand-off, non-nuclear primary schemes, including pulsed power machines, charged particle accelerators, plasma guns, and hypervelocity pellet guns.

In Fall 1960, I made key advances in the design of the fusion capsule to increase the energy gain. I eliminated the dense inert shell, began to optimize the temporal shape of the pulse of energy from the stand-off primary, and used a hollow shell of fusion fuel. These advances enabled achievement of highly efficient implosions. With optimum pulse shaping, ignition occurred in a central heat spot of the spherical implosion and TN burn propagated outward to ignite near-isentropically compressed DT. (Figure 6)

In late 1960, lasing was achieved experimentally by T. Maiman at Hughes. The coherent beam of laser light can be focused several meters from the wall of an explosion chamber into a tiny hohlraum. The laser's stand-off capability and its capability for generating an optimal pulse shape are extremely important for IFE applications.

In 1961-1962, Ray Kidder made calculations in which the surface of a fusion capsule was ablated directly by a high power pulse of spherically symmetric laser light. An advantage of the direct implosion is no energy losses to a hohlraum. A disadvantage is reduced ablative stabilization of the implosion. Also, direct implosions are not as well suited to IFE, because laser 
beams must be focused through a large number of holes in the explosion chamber.

In the 1961-62 time period, Livermore colleagues Stirling Colgate and Ron Zabawski made calculations in which a DT mass as small as one microgram was imploded to ignition by use of a fusion capsule with two dense shells.

There remained economic objections to IFE. For example, electrical energy cost 0.3 cents per Kwh, or approximately one cent for $10^{7} \mathrm{~J}$. How could a fusion capsule be manufactured for a few cents? In early 1961, I addressed this objection by producing a computer calculation of the radiation implosion of a spherical droplet of DT. (Figure 7) A liquid droplet can be cheaply "manufactured" with an eye-dropper. The mini-hohlraum can also be made very cheaply. Tritium can be regenerated via the $\mathrm{n}, \mathrm{Li}^{6}$ reaction in the chamber wall. However, we could not estimate the costs of lasers and other drivers, etc.

A long-term IFE strategy was evident in 1961: Develop suitable lasers and scale them up from less than a joule to $10^{6} \mathrm{~J}$; and develop efficient, milligram scale, high gain fusion capsules. However, Livermore did not take IFE seriously. My high gain implosions were extremely novel, drivers were not yet developed, and experts believed that MFE power plants would soon be demonstrated. Fortunately, ICF has weapons physics applications, so that the weapons program funded its development. 
In 1962-63, Livermore Director John Foster together with Edward Teller decided to start a small experimental laser fusion program, directed by Ray Kidder. Nuclear experiments were also initiated to explore ignition of small DT masses, and to test the stability of implosions driven by strong pulse shapes.

Livermore's early steps toward IFE - concepts, calculations, and experiments - positioned the Laboratory to launch the world's leading laser fusion program when the major opportunity arose in the early 1970s. This opportunity was driven by many forces, including the rise of KMS Fusion, advances in solid state and $\mathrm{CO}_{2}$ lasers, development of the electron implosion and declassification of optimistic calculations, the global energy crisis, and reports of aggressive Russian laser fusion programs.

The aggressive new Livermore program made rapid progress including the construction of the world's most powerful lasers (SHIVA then NOVA) and in the achievement of a laser driven radiation implosion followed by compression of DT to 100 times liquid density. (Figure 8)

Our Russian colleagues have mentioned early work on ICF by Sakahrov and others. Hopefully, Sakahrov's colleagues and successors will be able to report on this early work in Russia. 
Figure 1

\section{Two key questions and answers (1958-1960)}

1. What is smallest possible high gain fusion explosion?

Answer:

- less than $10^{-3} \mathrm{~g}$ of DT; $10^{6} \mathrm{~J}$ to implode/ignite

- compress 1000 fold via mini radiation implosion

2. How to drive radiation implosion without fission primary?

Answer: develop "non-nuclear primary" with stand-off, repetitive, pulse shaping potential 
Figure 2

\section{Micro-fusion approach to IFE (1959-1960)}

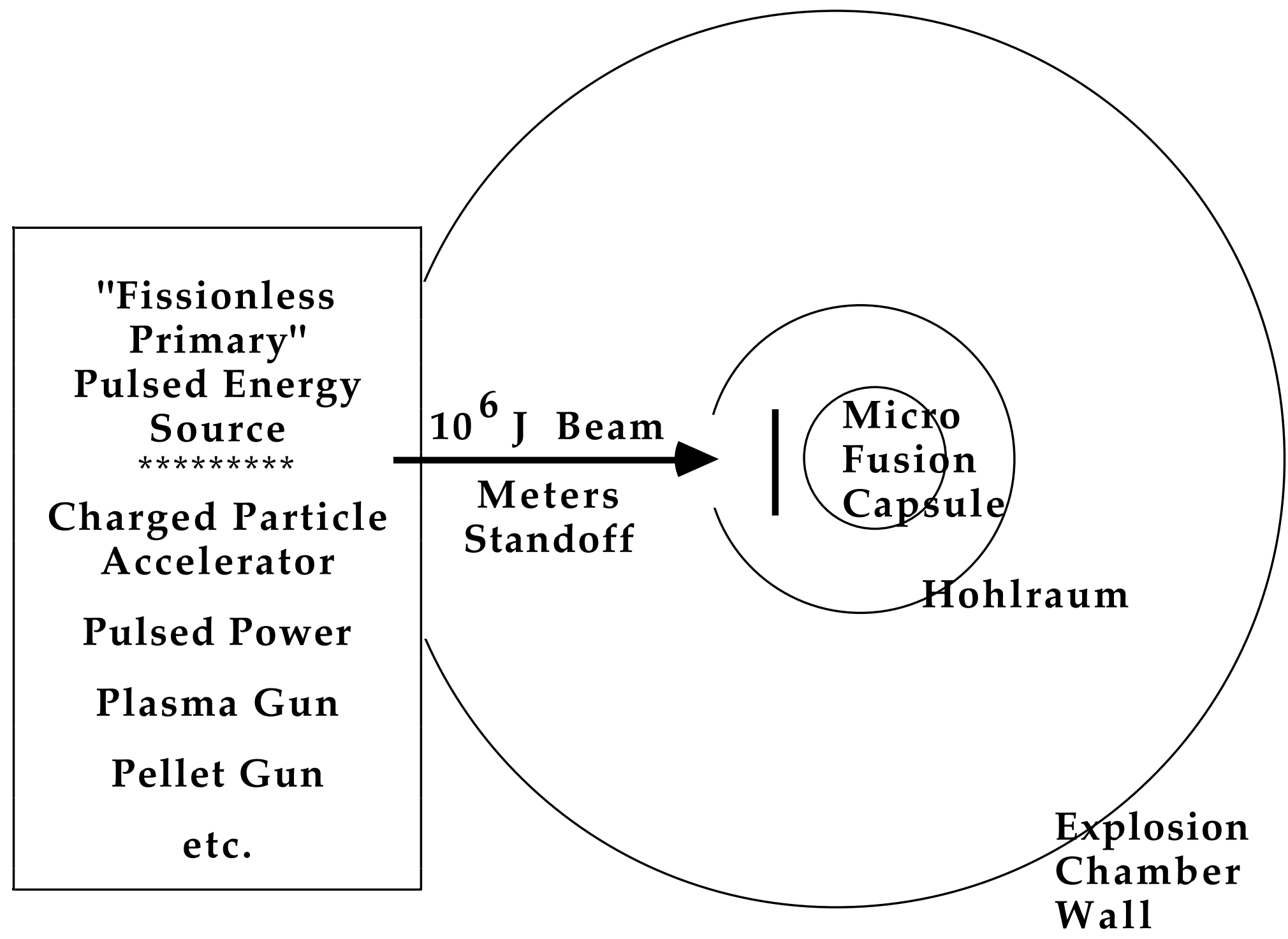




\section{Figure 3}

\section{Chronology}

H-bomb

Large-scale $\mathrm{H}$-bomb driven power plant

Micro-fusion driven power plant

Radiation implosion of one milligram of DT

High gain fusion capsule

(pulse shaping, elimination of inert shells)

Stand-off, fissionless, repetitive energy source
Concept/Test 1950-52

Analysis 1957

Concept 1959-60

Calculation 1960

Calculation 1960

Search $\quad 1960$ 
Figure 4

\section{Chronology (continued)}

Laser demonstrated

(T. Maiman, Hughes)

Low cost fusion capsule design

Direct laser implosion

UGT program started to demonstrate feasibility

Livermore laser fusion program started

Laser driven radiation implosion
Experiment 1960-61

Calculation 1961

Calculation 1962

Experiments 1962-

1962-63

Experiments 1976- 
Figure 5

\section{Calculation of radiation implosion of $10^{-3} \mathrm{~g}$ DT (1960)}

Low initial DT density $\left(0.01 \mathrm{~g} / \mathrm{cm}^{3}\right)$

DT contained by thin dense shell

Hohlraum temperature $240 \mathrm{ev}$

Compression of DT to $>50 \mathrm{~g} / \mathrm{cm}^{3}$

Burn efficiency $>50 \%$

Gain 10 (5 MJ input, $50 \mathrm{MJ}$ fusion) 
Figure 6

\section{Design of fusion implosion to achieve high gains}

(1960-1961)

Use hollow spherical shell of fuel

Eliminate inert shells

Optimally vary implosion pressure during implosion to:

- achieve efficient (isentropic) compression in most of fuel

- achieve ignition temperature in center, and initiate outward $\mathrm{TN}$ detonation wave 


\section{Figure 7}

\section{Low cost high gain fusion capsule design (1961)}

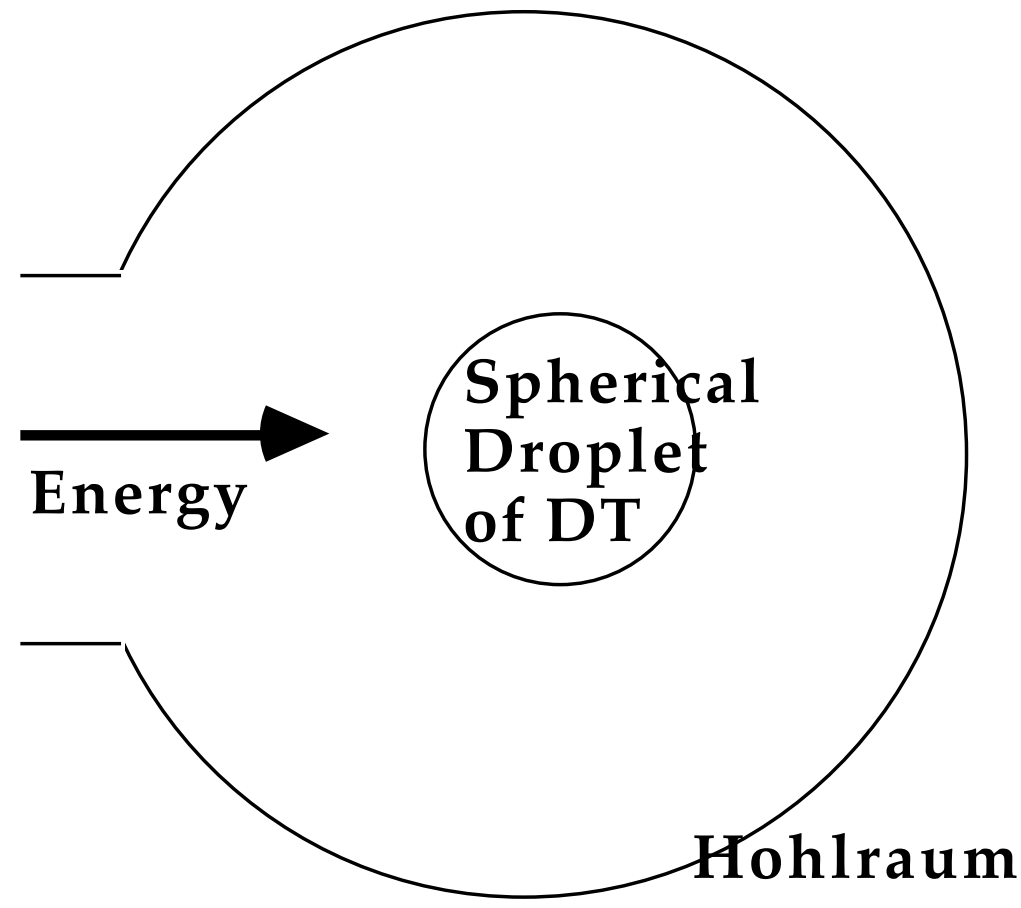

Capsule

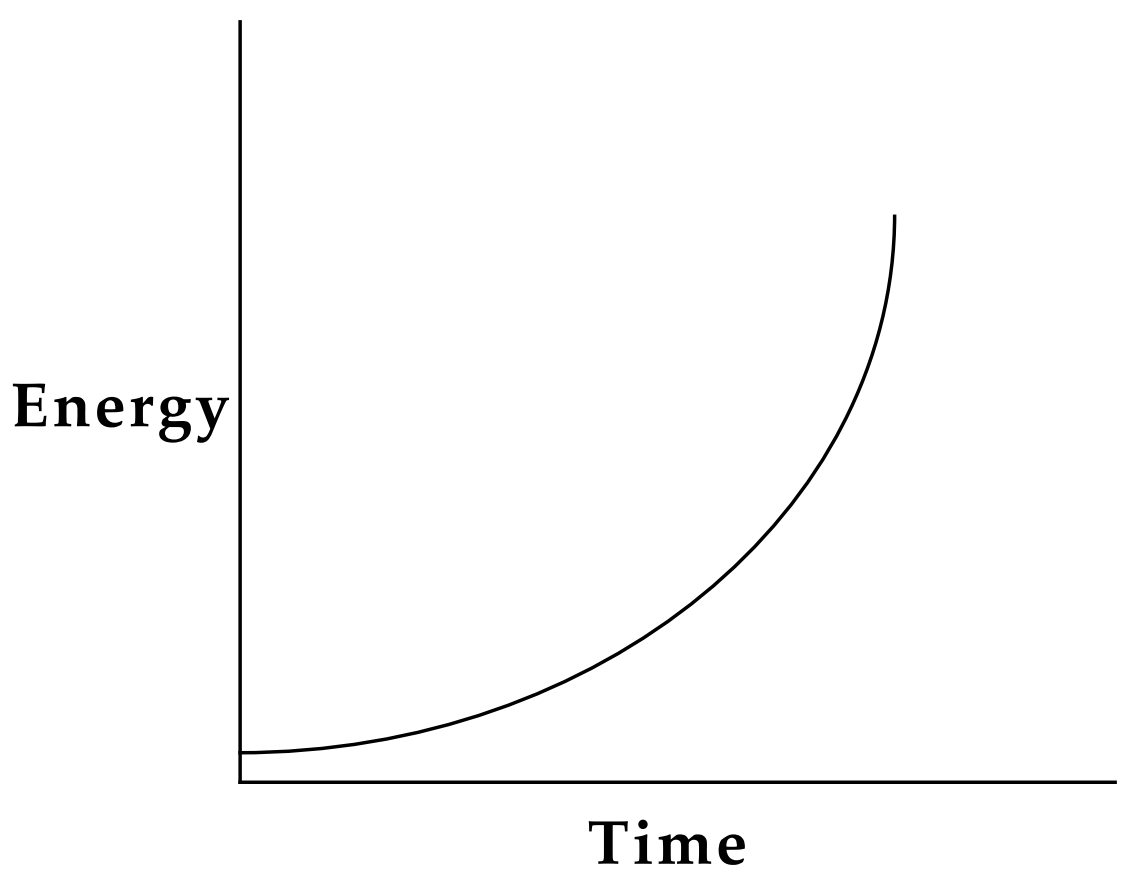

Pulse Shape

Implosion to $1000 \mathrm{~g} / \mathrm{cm}^{3}$, Ignition (from center) 
Figure 8

\section{First laser driven radiation implosion experiment (1976)}

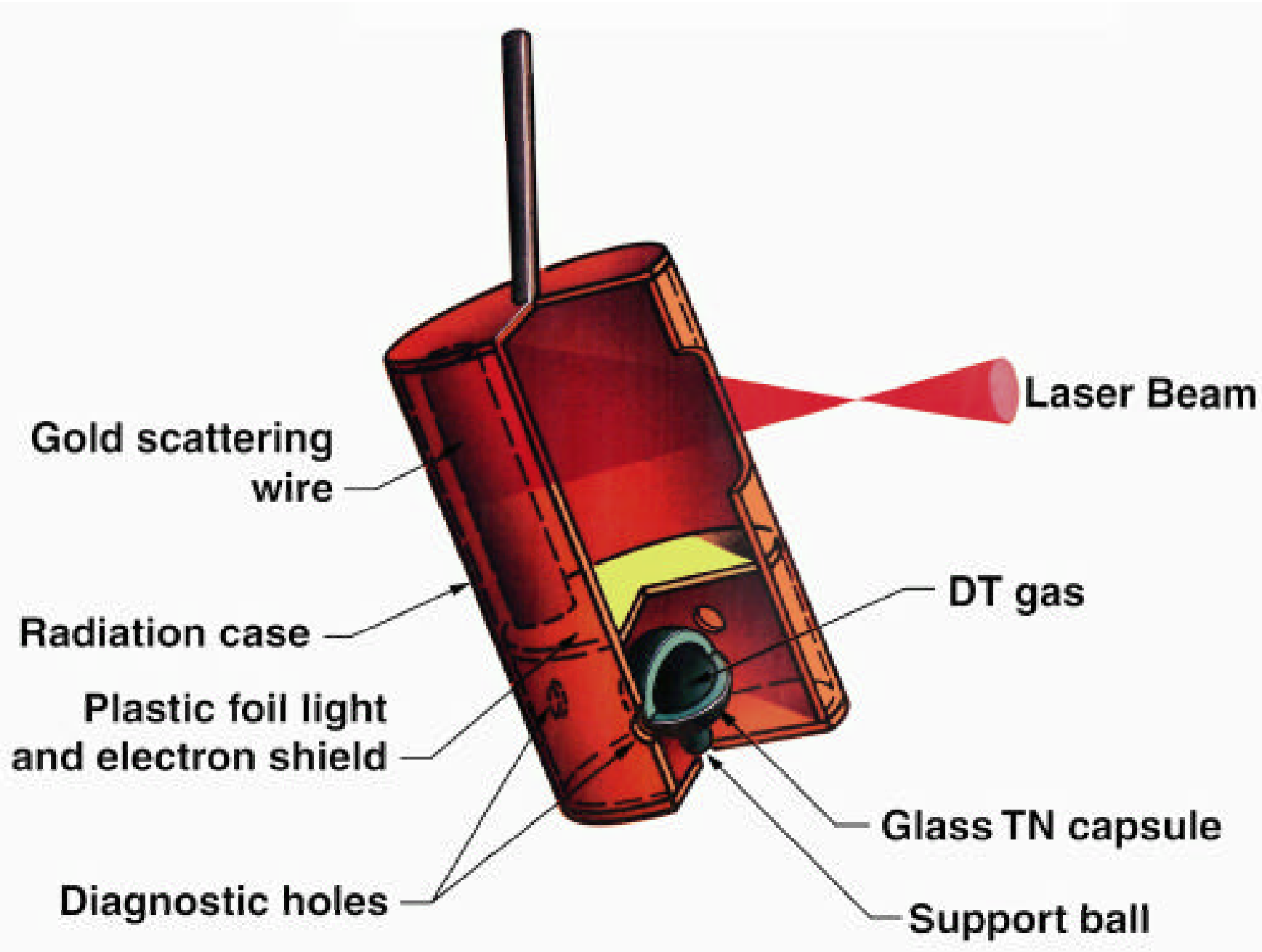

$1 \mathrm{~mm}$

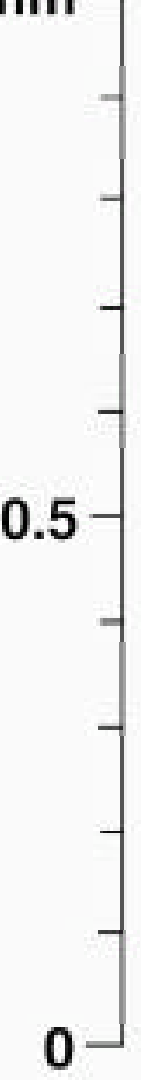

Prediction 6000 neutrons

Experiment 3000-9000 neutrons 


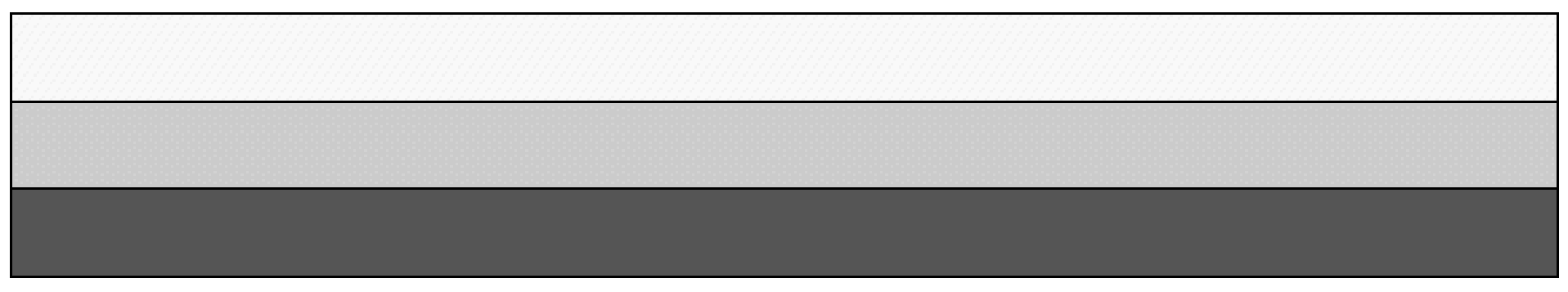

